\title{
Therapeutic apheresis in autoimmune diseases
}

This article was published in the following Dove Press journal:

Open Access Rheumatology: Research and Reviews

13 November 2013

Number of times this article has been viewed

\section{Rolf Bambauer' \\ Reinhard Latza ${ }^{2}$ \\ Carolin Bambauer ${ }^{3}$ \\ Daniel Burgard ${ }^{4}$ \\ Ralf Schiel ${ }^{5}$}

'Institute for Blood Purification, Homburg, ${ }^{2}$ Laboratorium of Medicine, St Ingbert, ${ }^{3}$ Main Hospital Darmstadt,

Darmstadt, ${ }^{4}$ Herz Zentrum,

Cardiology, Völklingen, ${ }^{5}$ Inselklinik

Heringsdorf GmbH, Seeheilbad

Heringsdorf, Germany
Correspondence: Rolf Bambauer Institute for Blood Purification, Frankenstrasse 4, 66424 Homburg, Germany

Tel +490684168500

$\mathrm{Fax}+490684168561$

Email rolf.bambauer@t-online.de
Abstract: Systemic autoimmune diseases based on an immune pathogenesis produce autoantibodies and circulating immune complexes, which cause inflammation in the tissues of various organs. In most cases, these diseases have a bad prognosis without treatment. Therapeutic apheresis in combination with immunosuppressive therapies has led to a steady increase in survival rates over the last 35 years. Here we provide an overview of the most important pathogenic aspects indicating that therapeutic apheresis can be a supportive therapy in some systemic autoimmune diseases, such as systemic lupus erythematosus, antiphospholipid syndrome, rheumatoid arthritis, and inflammatory eye disease. With the introduction of novel and effective biologic agents, therapeutic apheresis is indicated only in severe cases, such as in rapid progression despite immunosuppressive therapy and/or biologic agents, and in patients with renal involvement, acute generalized vasculitis, thrombocytopenia, leucopenia, pulmonary, cardiac, or cerebral involvement. In mild forms of autoimmune disease, treatment with immunosuppressive therapies and/or biologic agents seems to be sufficient. The prognosis of autoimmune diseases with varying organ manifestations has improved considerably in recent years, due in part to very aggressive therapy schemes.

Keywords: therapeutic apheresis, autoimmune diseases, systemic lupus erythematosus, antiphospholipid syndrome, rheumatoid arthritis, inflammatory eye disease

\section{Introduction}

The terms "systemic autoimmune disease" and "collagen vascular disease" describe a number of illnesses, the common characteristic of which is immune-mediated destruction of intracellular structures in connective tissue, resulting in fibrinoid tissue damage. ${ }^{1}$ Systemic autoimmune diseases, with the exception of rheumatoid arthritis and autoimmune thyroiditis, are individually rare, but together affect approximately $5 \%$ of the population in western countries. They are a fascinating but poorly understood group of diseases. ${ }^{2}$ Based on an immune pathogenesis, the various organs form antigen components, which provoke formation of autoantibodies on the one hand, and circulating immune complexes causing inflammation in organ tissues on the other.

Viral infections can probably change the antigenic surface structure of the body's own cells in such a way that the relationship between the altered cell and the immune system is changed and cells of the body are not recognized by the immune system. In this way, viral infections and other influences can lead to altered native antigens with a loss of suppression. ${ }^{3}$ With regard to formation of antibodies against the body's structures, physiologic low-titer immunoglobulin (Ig)M autoantibodies with low affinity and broad specificity must be differentiated from IgG and IgA autoantibodies with high affinity. 
The former play a role in cell decomposition and tissue turnover, while the latter mostly cause immunopathologic disorders, either through formation of circulating immune complexes or through direct tissue-specific lesions. ${ }^{4}$

Typically, antinuclear antibodies are to be found against most nuclear structures. There are typically antibodies directed against both cytoplasmic-associated and cell membrane-associated proteins, and also antibodies against cytoplasmic structures and cell membrane components. The range of antibodies observed in active and subclinical disease includes those against many extracellular antigens, such as collagen, myelin sheaths, immunoglobulins, basement membrane, intercellular bridges, hormones, and complement components. ${ }^{5}$ There is mounting evidence to suggest an active role for the indications increasing that point to an immunopathologic role of autoreactive $\mathrm{T}$ cells, in addition to autoantibody-producing plasma cells. This evidence is consistent with the clinical observation that the vast majority of hypothesis is supported by the fact that, on the one hand, all chronic autoimmune diseases are associated with certain human leucocyte antibody HLA haptotypes and on the other, autoreactive $\mathrm{T}$ cells can cause tissue damage by release of mediators and toxins. ${ }^{6}$

Vasculitis is common to all these diseases, and is most easily demonstrated histologically in the precapillary arterioles and post-capillary venuoles. The same chronic cellular infiltrates are seen in immune-mediated synovitis, with its clinical manifestations of arthralgia or arthritis.

These antibodies have been directly implicated in causing tissue damage in some diseases. Humoral autoimmunity was at center stage in the 1970s and 1980s, and various therapeutic approaches were designed to interfere specifically with production of autoantibodies or to remove autoantibodies from the circulation. Therapeutic plasma exchange (TPE) was explored in the treatment of a variety of autoimmune syndromes, including systemic lupus erythematosus (SLE), rheumatoid arthritis, and vasculitis. Therapeutic plasma exchange is still accepted to have a role in thrombotic thrombocytopenic purpura and cryoglobulinemia; however, in other chronic inflammatory diseases, therapeutic plasma exchange has had disappointing results. ${ }^{7}$

After 1990, treatment strategies no longer focused on the B cell and removal of autoantibodies, but rather focused on effector mechanisms involving macrophages and the cytokines produced as part of the inflammatory response. The success of recent pilot studies exploring B cell depletion as a therapeutic strategy was unexpected and has renewed interest in reconsidering the role of the $\mathrm{B}$ cell in these diseases. ${ }^{8,9}$
In the following sections of this paper, we discuss the indications for therapeutic apheresis in autoimmune diseases such as SLE, antiphospholipid syndrome, rheumatoid arthritis, and inflammatory eye disease from a pathophysiologic point of view, and the clinical results that have been obtained using this approach. Therapeutic apheresis methods, such as TPE, and the different semiselective or selective plasma exchange methods available are discussed in detail by Bambauer et al. ${ }^{10}$

\section{Systemic lupus erythematosus}

Systemic lupus erythematosus is an autoimmune disease characterized by hypergammaglobulinemia, the presence of various autoantibodies, and immunoregulatory alteration. Among the autoantibodies, anti-double-stranded (ds)DNA is highly specific for the disease and is thought to play an important role in its pathogenesis. ${ }^{11}$ Anti-dsDNA autoantibodies constitute a heterogeneous family with respect to avidity, cationic charge, immunoglobulin class, and complementfixing ability. ${ }^{11,12}$

Systemic lupus erythematosus usually involves high-titer antinuclear antibodies of the IgG group. This antinuclear antibody group includes not only the anti-dsDNA antibodies but also autoantibodies against single-stranded DNA (ssDNA), histones (H1-H4), and non-histone proteins (eg, Sm, nRNP, SS-A/Ro, SS-B/La). ${ }^{13}$ Thus, in addition to antinuclear antibodies, SLE patients possess, although less frequently, autoantibodies against cytoplasmic antigens (SS-A/Ro, SS-B/La, ribosomes, Golgi apparatus), phospholipids (eg, cardiolipin), cytoskeletal proteins (eg, cytokeratin, desmin, vimentin, neurofilaments), basement membrane, and various cell superior determinants of leucocytes, erythrocytes, and thrombocytes (Table 1).

Most antibodies belong to the so-called easy antigens, ie, they are long-chained structures with repetitive epitopes, such as DNA, RNA-cell surface antibody, and basement membrane. ${ }^{11,13}$ Many of these antibodies are polyreactive, ie, show overlapping binding specificity for several antigens. The cause for the polyreactivity of anti-DNA antibodies is thought to be related to the fact that the various antigens have in common certain phosphate remains in a similar conformation or that the antigen binding site of autoantibodies has various independent binding sites. ${ }^{11}$

It is still unclear whether formation of antinuclear antibodies is due to altered (and thus immunogenic) DNA, polyclonal activation of $\mathrm{B}$ cells, cross-reaction with bacterial antigens, or a genetically induced disorder of immune regulation. The importance of genetic factors is not only underscored by the 
Table I Autoantibodies in systemic lupus erythematosus

Antibodies against cytoplasmic antigens

- SS-A/Ro

- Ribosomal RNA

- Golgi apparatus

- Cytoskeletal proteins (keratin, vimentin, desmin, neurofilaments)

Antibodies against basement membrane

Antibodies against cell surface determinants

- Antilymphocytic antibodies specific for $\beta 2$-microglobulin

- MHC I and II antigens

- Non-MHC antigens (eg, chronic lymphocytic leukemia and lymphoblasts)

- T cell subsets (eg, CD4+ and CD8+)

- Antileucocytic antibodies

- Antierythrocytic antibodies

- Antithrombocytic antibodies

- Antineuronal antibodies (extensive cross-reaction with antilymphocytic antibodies)

- Membrane phospholipid (eg, anticardiolipin antibodies)

- Heat shock proteins

- Trophoblast antigens

Antibodies against serum components

- Immunoglobulins (rheumatoid factors)

- Coagulation factors (lupus anticoagulants)

- Complement components (nephritogenic factor)

Note: Reproduced with permission from Bambauer R, Latza R, Lentz MR. Therapeutic Plasma Exchange and Selective Plasma Separation Methods, Fundamental Technologies, Pathology and Clinical Results. 3rd ed. Berlin, Germany: Pabst Sciences Publishers; 2009. ${ }^{33}$

Abbreviation: MHC, major histocompatibility complex.

above-mentioned relationship between human leucocytes and antibodies, but also by recent immunologic analyses of anti-DNA autoantibodies in mice and humans.

Natural CD4+ CD25+ regulatory T cells (Tregs) have a potent immunosuppressive function and contribute to immunologic self-tolerance by suppressing potentially autoreactive T cells. Depletion of these cells leads to destruction of severe autoimmune diseases in animal models; more recently, there have been studies reporting impairment of Treg numbers and/or function in various human autoimmune diseases. ${ }^{14}$

Valencia et al hypothesized that altered function of CD4+ $\mathrm{CD} 25+$ Tregs might play a role in the breakdown of immunologic self-tolerance in patients with SLE. They reported a significant decrease in the suppressive function of CD4+ CD25+ Tregs in the peripheral blood of patients with active SLE as compared with normal blood donors and patients with inactive SLE. ${ }^{15}$

The tissue damage is caused by deposition of circulating immune complexes in various organs. Primarily involved are the smaller and medium-sized arteries of the skin, joints, lungs, liver, brain, kidneys, glomeruli, peritubular renal capillaries, and epidermal basement membrane..$^{13}$

The capillary wall in the glomerulus possesses a fenestrated endothelium under which is located the negatively charged basement membrane with its various structures. Due to its electric charge and composition, the basement membrane creates both a molecule size and an electric charge barrier for proteins from the blood. ${ }^{16}$ The subendothelial area is in direct contact with the mesangium, which has a rinsing and cleansing function in the glomerulus and is a potential site for local inflammation. ${ }^{13}$ Mesangial, subendothelial, and subepithelial immune complex deposits are found in lupus nephritis and other forms of glomerulonephritis. If they persist, subendothelial-deposited immune complexes show condensation and an increase in size, causing further destruction.

Cationic antigens or antibodies can also bind to the negatively charged lamina rara externa of the basement membrane, and through secondary deposition of autoantibodies or antigens, a local immune complex formation can arise. ${ }^{17}$ A state of illness begins when the antibody response leads to an increase in circulating foreign proteins. The difference in the speed at which cationic antigens are processed in the different tissues also seems to play an important part in the occurrence of immunopathologic lesions.

Systemic lupus erythematosus is a chronic inflammatory disorder. ${ }^{18}$ With its extremely variable range of symptoms, SLE can cause broadly varying clinical conditions, ranging from an acute attack with high temperature, anemia, leucopenia and thrombocytopenia, arthritis, exanthema, and polyserositis, to lasting isolated damage to the kidneys, bone marrow, and joints. ${ }^{19}$ The disease preferentially affects childbearing age females (ratio F:M 10:1). ${ }^{18}$ The course of SLE is often unpredictable, with many attacks and milder forms of SLE showing spontaneous remission. Mortality of $70 \%$ at 10 years is typically, due to infections and renal failure. Renal involvement in SLE is associated with high mortality. ${ }^{18}$ With aggressive therapeutic schemes, survival rates have been steadily increasing in recent years. ${ }^{20}$ In 1988 , the American Rheumatology Association compiled the seven most important diagnostic criteria for SLE. ${ }^{21}$

The course of SLE is often unpredictable, with many attacks and milder forms of SLE showing spontaneous remission. With aggressive therapeutic schemes, survival rates have been steadily increasing in recent years. ${ }^{20}$ In 1988 , the American Rheumatology Association compiled the seven most important diagnostic criteria for SLE. ${ }^{21}$ According to these criteria, the diagnosis is made based on typical clinical symptoms and particularly on serologic detection of antinuclear antibodies, DNA antibodies (ssDNA and dsDNA), as well as on numerous other autoantibodies and organ biopsies. ${ }^{22}$ Nonspecific parameters include an increased level of IgG, as well as decreased serum concentrations of $\mathrm{C} 3$ 
and C4 during acute attacks. Granular immunoglobulin and complement deposits can frequently be detected in affected skin by direct immunofluorescence.

Apart from treatment with corticosteroids, chloroquine, antimetabolites such as azathioprine or methotrexate, and immunosuppressives such as cyclophosphamide, the prognosis has become even better with intensive steroid therapy and TPE combined with immunosuppressive therapy. ${ }^{13,23,24}$ SLE is an autoimmune disease involving increased production of autoantibodies, immune complex deposition in the microvasculature of various organs, complement activation, leukocyte infiltration, and tissue damage. The immune complex glomerulonephritis of SLE is a major cause of morbidity and a determinant of the outcome of the disease. ${ }^{25}$ Advances are needed in the treatment of severe lupus erythematosus, both to reduce the current mortality rate of $10 \%-20 \%$ after 10 years and to decrease the development of renal insufficiency requiring dialysis, which occurs in nearly one quarter of patients. Also, efforts must continue to minimize the adverse effects of long-term immunosuppressive therapy. ${ }^{26}$

While it is still not understood how TPE actually works in SLE since its first implementation by Jones et al in $1978,{ }^{27}$ many authors are of the opinion that TPE has considerably extended the therapeutic concept. ${ }^{28-32}$

The authors published a selection of literature on SLE including 286 patients treated with TPE since its introduction in 1976, in addition to immunosuppressive therapy. Some of the literature included uncontrolled studies. In at least 210 patients $(73 \%)$, partial or full remission was observed temporarily or for up to many months in some cases, enabling a dramatic reduction in immunosuppressive therapy. ${ }^{33}$
The volume treated is $1.0-1.5$ of total plasma volume, the replacement fluid is an albumin-electrolyte solution, and the frequency for lupus cerebritis is daily or every other day. Typically, a course of 3-6 TPE is sufficient to achieve a response in patients with lupus cerebritis. Prolonged treatments have been reported, but their rationale and efficacy is questionable. ${ }^{18}$ Table 2 summarizes the guidelines for use of therapeutic apheresis in SLE.

TPE is particularly indicated in severe cases, such as in: - rapid progression despite immunosuppressive therapy ${ }^{34}$

- renal involvement, eg, proliferative glomerulonephritis and nephrotic syndrome ${ }^{35-37}$

- extremely acute generalized vasculitis

- thrombocytopenia and leucopenia ${ }^{28,38}$

- pulmonary, cardiac, and cerebral involvement ${ }^{39,40}$

- pancreatitis. $^{41}$

Back in 1979, on the basis of 14 SLE patients, Jones et al were the first to report termination of an acute exacerbation of severe SLE, and demonstrated that TPE is particularly successful in the acute phase of the disease. ${ }^{27}$ Campion and Lewis also reported that plasmapheresis and standardized immunosuppressive therapy did not influence the prognosis for patients with lupus nephritis. ${ }^{41,42}$ However, other authors are of the opinion that it would be premature to conclude that plasmapheresis is ineffective in this disease. It seems that TPE is most effective when the signs and symptoms of an acute flare are dramatic. ${ }^{37}$

A potential disadvantage of the studies reported to date is that the immunologic effects of plasmapheresis itself have not been sufficiently studied. Studies of the production of specific antibodies show that this is influenced by regulatory biological mechanisms. High concentrations of

Table 2 Guidelines on the use of therapeutic apheresis in systemic lupus erythematosus, catastrophic antiphospholipid syndrome, and rheumatoid arthritis

\begin{tabular}{|c|c|c|c|c|c|c|}
\hline & \multicolumn{3}{|c|}{$\begin{array}{l}\text { German Working Group of } \\
\text { Clinical Nephrology, } 2002^{92}\end{array}$} & \multicolumn{3}{|c|}{$\begin{array}{l}\text { Apheresis Applications Committee } \\
\text { of ASFA, 2007, } 2010^{18,59}\end{array}$} \\
\hline & $\begin{array}{l}\text { TA } \\
\text { modality }\end{array}$ & $\begin{array}{l}\text { Evidence } \\
\text { class }\end{array}$ & $\begin{array}{l}\text { Severity } \\
\text { grade }\end{array}$ & $\begin{array}{l}\text { TA } \\
\text { modality }\end{array}$ & Category & $\begin{array}{l}\text { Recommendation } \\
\text { grade }\end{array}$ \\
\hline Systemic lupus & IA-Protein-A & & & & & \\
\hline erythematosus & Peptid GAM ${ }^{\circledR}$ & III & B & TPE & II & $2 C$ \\
\hline (severe) & Tryptophan & & & & & \\
\hline Lupus nephritis & Dextran sulfate & & & TPE & IV & \\
\hline Catastrophic & IA-Protein-A & & & & & \\
\hline antiphospholipid & Peptid GAM ${ }^{\circledR}$ & III & C & TPE & III & $2 \mathrm{C}$ \\
\hline \multirow[t]{2}{*}{ syndrome } & Tryptophan & & & & & \\
\hline & Dextran sulfate & & & & & \\
\hline Rheumatoid & IA-Protein-A & $\mathrm{lb}$ & A & TPE & 1 & - \\
\hline arthritis & Peptid GAM ${ }^{\circledR}$ & & & IA-Protein-A & II & $2 \mathrm{~A}$ \\
\hline
\end{tabular}

Abbreviations: ASFA, American Society for Apheresis; TPE, therapeutic plasma exchange; TA, therapeutic apheresis. 
an antibody inhibit its further synthesis, and conversely, short-term elimination of an antibody results in increased compensatory production. ${ }^{23}$ In extreme cases, this can lead to excessive antibody levels after plasmapheresis. Thus, many of the studies aimed at suppressing this rebound effect after plasmapheresis by means of corresponding immunosuppression.

Increased production of pathogenic antibodies probably goes hand in hand with increased activity of lymphocytic clones, and thus with increased vulnerability toward cytotoxic substances. A protocol based on this theory should, therefore, combine several large-volume plasmapheresis treatments with immediate subsequent pulse cyclophosphamide therapy. This procedure aims not only to provide short-term relief for the patient in terms of pathogenic material, but also to intensify damage to pathogenic lymphocyte clones. $^{43-45}$

The combination of plasmapheresis and subsequent highdose cyclophosphamide therapy leads not only to inhibition of progression, but also to years of completely therapy-free, long-term remission. This strategy has been found to be very effective. However, in view of the risks of this aggressive concept, it should only be implemented in treatment-resistant cases. The status of this synchronized concept was examined in another randomized study which was intended to determine the optimal conditions for this combination, but this work was not completed. ${ }^{45-47}$

Aringer et al treated 21 patients with high SLE activity using TPE and pulse cyclophosphamide $(n=9)$ or pulse cyclophosphamide alone $(n=12) .{ }^{48}$ They found that seven of nine TPE-treated patients had serious bacterial or viral infections, including three cases of cytomegalovirus infection. Among the 12 patients treated with pulse cyclophosphamide alone, only two had severe infections. Three patients in the TPE group and none in the control group died of infection. However, treatment efficacy was similar for both groups. In the patients who received TPE and pulse cyclophosphamide, life-threatening bacterial and viral infections and mortality occurred more frequently than in patients with similarly active SLE treated with pulse cyclophosphamide alone. ${ }^{48}$

Other investigators saw only in patients with higher disease activity a combination of TPE and pulse cyclophosphamide indicated. In the most of the severe cases pulse cyclophosphamide alone may improve the final outcome. ${ }^{49}$ The concept of treatment using a combination of TPE and subsequent high-dose cyclophosphamide is not widely accepted in the clinical setting. Pagnoux et al found that TPE may still be of relevance as adjunctive therapy in selected SLE patients. ${ }^{50}$

Repeated TPE in SLE patients can induce a significant increase in the number of peripheral CD4+ CD25highFoxP3+ T cells in parallel with a decrease in the SLE Disease Activity Index. This phenomenon, among others, is possibly due to elimination of interferon- $\alpha$ and lymphocytotoxic antibodies during TPE. ${ }^{51}$

The extent to which regular TPE can improve the prognosis in patients with chronic SLE is still not clear. According to Clark et al, TPE with four liters once per month probably modulates the immune response and thus intervenes beneficially in the course of the disease. ${ }^{52}$ This observation is also confirmed by many years of own experiences by Bambauer et al. ${ }^{33}$

Cyclosporin is a well known immunosuppressive drug which has been used successfully for many years to delay organ transplant rejection in particular. Cyclosporin A seems to be promising in the management of autoimmune diseases, and via a similar mechanism of immune suppression as observed in animal experiments and in vitro studies. Routine use implementation of cyclosporin A in chronic SLE presents new therapeutic possibilities due to selective inhibition of T cell activity at a very early stage. ${ }^{53}$

Investigations have shown that, after intensive treatment of SLE patients in the acute phase using TPE, cyclosporin A enabled both a drastic reduction in TPE frequency and a discontinuation or reduction of immunosuppressive corticosteroid and azathioprine medication by $70 \%-90 \% .^{54,55}$ However, any influence on the survival rate remains questionable. Reports of exacerbation of lupus by cyclosporin A and in particular of the medium to considerable nephrotoxicity, suggest that it should be used with caution in this disease, and support the argument for strict indications regarding use of this agent. ${ }^{56-58}$ Further controlled studies will be necessary to clarify which is the most effective therapeutic combination for SLE and the manifestations of this complex disease that are best controlled using particular therapeutic options.

The guidelines for use of therapeutic apheresis published by the Apheresis Applications Committee of the American Society for Apheresis put SLE (severe cases) in category II and lupus nephritis in category IV. ${ }^{18,59}$

In the early 1980 s it was reported that more than 50\% of patients with various manifestations of SLE improved after TPE. ${ }^{18}$ The use of cyclosporine A and TPE to control symptomatic diseases resulted in quicker resolution of symptoms and decreased doses of cytotoxic drugs. Patients with 
SLE and CNS involvement who were treated with TPE or combination TPE/cyclophosphamide showed a high percentage of improvement. ${ }^{18}$

In the last couple of years, other authors have recommended supportive therapeutic apheresis as an important rescue treatment for SLE in combination with immunosuppressive therapy and/or biologic agents. ${ }^{60}$

In summary, the prognosis for SLE with varying organ manifestations has been considerably improved in recent years due in part to very aggressive therapy schemes. The use of immunoadsorption in combination with recently developed biologics might offer new perspectives for the extracorporeal treatment of SLE. ${ }^{61}$

\section{Antiphospholipid syndrome}

Antiphospholipid syndrome is an autoimmune hypercoagulable state caused by antibodies against cell membrane phospholipids that provoke thrombosis in the arteries and veins. Antiphospholipid antibodies can be detected by measuring lupus anticoagulant and anticardiolipin antibodies. ${ }^{62}$ Antiphospholipid antibodies are implicated in vascular thrombosis, thrombocytopenia, and recurrent fetal loss in patients with SLE. The etiology of thrombosis of the small and large vessels is not completely understood. Involvement of the kidneys in antiphospholipid syndrome is possible. In addition to thrombosis of the great arteries and veins, microscopic thrombotic microangiopathy is typically observed on kidney histology. High levels of antiphospholipid antibodies in patients with SLE increase the risk of venous and arterial thrombosis, adverse cerebrovascular events, recurrent fetal loss, and other arterial thrombotic and embolic complications, such as superior mesenteric artery thrombosis and thrombocytopenia. While antiphospholipid syndrome can exist without SLE, it should also be considered in non-SLE patients when classical symptoms, such as recurrent thrombosis of unknown etiology, are present. Therapeutic apheresis can be considered life-saving in patients with severe antiphospholipid syndrome. ${ }^{63}$

Catastrophic antiphospholipid syndrome (CAPS) is an unusual variant of antiphospholipid syndrome. "CAPS is defined as the acute onset of multiple thrombosis in at least three organ systems over a period of days or weeks, in patients with serologic evidence of antiphospholipid antibodies (lupus anticoagulant, anticardiolipin antibodies, and/or anti- $\beta 2$ glycoprotein I). The most commonly affected sites are small vessels of kidneys, lungs, brain, heart, and skin, although large vessel thrombosis can also be present. Common manifestations include renal failure, acute respiratory distress syndrome, pulmonary embolism, livedo reticularis, purpura, skin necrosis, cerebral infarcts, encephalopathy, seizure, and cerebral venous occlusion. In addition, the systemic inflammatory response syndrome (SIRS) is a component of the acute phase of CAPS. Thrombocytopenia can be marked, over 33 percent of patients have hemolysis, and 20 percent present with disseminated intravascular coagulation. CAPS may be the first manifestation of antiphospholipid syndrome ('de novo') or complicate the course of patients known to have the syndrome. Mortality approaches 50 percent and is mainly due to myocardial thrombosis with or without respiratory failure." 18

The exact mechanism by which TPE exerts an effect in CAPS is not known, but removal of pathologic antiphospholipid antibodies, as well as cytokines, tumor necrosis factor-alpha (TNF- $\alpha$ ), and complement, is thought to play an important role. Further, given that plasma has been the replacement in most reports, transfusion of natural anticoagulants such as protein $\mathrm{C}$, protein $\mathrm{S}$, and antithrombin may contribute to the overall benefit of this procedure. However, it has not been established if plasma transfusion alone would have similar benefits because this option has not been tested. The category III for TPE is assigned based on a paucity of data (Table 2). ${ }^{18}$

The optimal treatment of CAPS is still debatable given that the condition is rare and there have been no relevant prospective studies. However, the therapeutic approach has to have three aims:

- to treat any precipitating factors, eg, infection, organ necrosis

- to prevent and to control ongoing thrombosis

- to suppress excessive cytokine production. ${ }^{18}$

Szczepiorkowsky et al reported in 2007 as the most commonly employed therapy in CAPS a full anticoagulation with heparin, high dose corticosteroids, TPE, and IVIG. ${ }^{18}$ If CAPS is associated with a flare of SLE, cyclophosphamide is also used. In combination with infection parenteral antibiotics should be administered. ${ }^{18}$ A minimum of 3-5 TPE are recommended. Discontinuation is based on the patient' clinical response. Some patients have been treated for weeks.

From retrospective study data, Espinosa and Cervera concluded that first-line therapies should always include the combination of anticoagulation against thrombosis, glucocorticoids plus therapeutic apheresis, and/or intravenous immunoglobulins in the treatment of CAPS. ${ }^{64}$

\section{Rheumatoid arthritis}

Rheumatoid arthritis is an autoimmune disease that affects approximately $1 \%-3 \%$ of the population and results in 
considerable morbidity and debility. ${ }^{65}$ A typical characteristic of rheumatoid arthritis is that the joints are affected, with accompanying extra-articular manifestations, such as vasculitis as well as spleen and lymph node involvement. Recent evidence supports a central role for activated $\mathrm{T}$ cells in its pathogenesis. In the inflamed joints of patients with rheumatoid arthritis, activated $\mathrm{T}$ lymphocytes accumulate as activated cells. ${ }^{66}$ The etiology and pathogenesis of rheumatoid arthritis are still unclear for the most part. It is known that treatment of this disease is very difficult and even controversial. Most drugs have only limited efficacy. ${ }^{66,67}$

Rheumatoid arthtitis is a chronic multisystem autoimmune disease of unknown etiology. The most characteristic feature is an an inflammatory synovitis, it can be relapsing or persistent, usually involving peripheral joints in a symmetric distribution. ${ }^{18}$ In about $20 \%$ of the patients, there are extra-articular features. The role of antibodies to cyclic citrullinated peptides in the pathogenesis and diagnosis has been increasing attention. ${ }^{18}$

A positive rheumatoid factor can be serologically detected in about $80 \%$ of patients; antinuclear antibodies, circulating immune complexes, cryoglobulins, and hypergammaglobulins may also be present. The rheumatoid factors belong to the IgM and IgG group. The immune complexes can activate the complement system and, via subsequent activation of mononuclear and polymorphonuclear cells, cause tissue damage through release of proinflammatory cytokines, particularly TNF. 68

It has been shown that rheumatoid arthritis has significant systemic effects, with associated morbidity and mortality. ${ }^{9}$ The role of humoral versus immune activity in the resulting disease process is not completely understood, although recent data suggest both are involved. T cells are activated by an unknown initiating process, resulting in production of interleukin- 1 and TNF- $\alpha$, which have been shown to have a significant role in the inflammatory process. It is believed that autoantigens develop after initiation, perpetuating $\mathrm{T}$ cell activity and the disease process. Rheumatoid arthritis was previously thought of as a disease mediated primarily by $\mathrm{T}$ cells. ${ }^{69}$

The goals of therapy for rheumatoid arthritis are:

- relief of pain

- reduction of inflammation

- protection of articular structures

- maintenance of function

- control of systemic involvement

- healing of bone erosions.

None of the current therapeutic interventions is curative, and all must be viewed as palliative, aimed primarily at relieving the signs and symptoms of the disease. ${ }^{18}$ Medical management of rheumatoid arthritis can be divided conveniently into five groups of medications:

- Aspirin, other nonsteroidal anti-flammatory drugs, and simple analgesics,

- low-dose oral glucocorticoids,

- disease-modifying antirheumatic drugs (eg, methotrexate),

- cytokine-neuralizing agents (ie, anti-TNF, anti-IL-1)

- immunosuppressive, and cytotoxic drugs, and novel and effective biologic agents like rituximab. ${ }^{18}$

Because both cellular and humoral mechanisms are involved in the pathogenesis of rheumatoid arthritis, in recent years TPE, cryofiltration, lymphoplasmapheresis, and leukocytapheresis have been implemented in addition to immunosuppressive therapy in particularly severe cases. ${ }^{70-74}$ The clinical results of cryofiltration, double filtration, and leukocytapheresis are very encouraging; these methods could be a regular therapy for rheumatoid arthritis, particularly in those patients with poorly controlled disease on immune suppressive or anti-TNF therapy. ${ }^{75-79}$ In the guidelines for use of therapeutic apheresis published by the Apheresis Applications Committee, rheumatoid arthritis has for immunoadsorption with protein $\mathrm{A}$ the category II, and for TPE the category I. ${ }^{18,59}$

After the Apheresis Application Committee the rationale for using staphylococcal protein A column is that protein A has a high affinity for $\mathrm{Fc}$ portion of $\mathrm{IgG}$ and for high molecular weight IgG and IGM complexes (18). IgG antibodies and CICs can be selectively removed from the blood by perfusion of patient plasma through the columns. The removal or alteration of CICs by IA, could be immunomodulatory and potentially beneficial for patients with RA. Only small amounts of immunoglobulin are removed by IA ( $1 \%-3 \%$ of total serum Igs) and their concentration is unchanged, as are plasma levels of CICs. An indirect immunomodulatory mechanism is suggested in IA-induced therapeutic responses in RA. ${ }^{18}$

The usual treatment course is 12 weeks. In most studies, clinical improvement was delayed for up to a few weeks after completing the procedures.

The current management and treatment of rheumatoid arthritis is first to use the above-mentioned five groups of medications with aspirin and other nonsteroidal anti-inflammatory drugs, and lastly, immunosuppressive and cytotoxic drugs. There is a new class of drugs that can be used to target specific cells and cytokines, and is known 
as the "biological agents". These drugs have been shown to reduce inflammation significantly and to retard the progression of joint damage in rheumatoid arthritis, thereby reducing symptoms and improving function. ${ }^{80}$ Early clinical results of monotherapy using tocilizumab, anti-interleukin-6 receptor antibody, in rheumatoid arthritis were excellent. ${ }^{81}$ Therefore, therapeutic apheresis is only indicated in severe cases of rheumatoid arthritis if all five groups of drugs have failed. The excellent results mentioned previously may be one reason why production of Staphylococcal protein A agarose (Immunosorba $^{\circledR}$; Fresenius HemoCare GmbH, Bad Homburg, Germany) and Staphylococcal A silica (Prosorba ${ }^{\circledR}$; Fresenius HemoCare $\mathrm{GmbH}$ ) columns was discontinued in the United States in December 2006. However, these devices are available in other countries. ${ }^{18}$

\section{Inflammatory eye disease}

When conventional therapy with cortisone or immunosuppressive drugs fails or is inadequate in the treatment of immune-mediated inflammatory eye disease with an autoimmunologic pathogenesis, therapeutic apheresis may be indicated and is increasingly being implemented with success. By 1984, Wizemann et al had already reported successful treatment of chronic uveitis with TPE. ${ }^{82}$

Severe uveitis is potentially associated with visual impairment or blindness in young patients. ${ }^{83}$ In posterior uveitis, progredient inflammatory processes can lead to morphologic changes in the chorioidea and retina, contributing to functional deterioration. In uveitis intermedia, inflammatory processes in the peripheral retina and in the area of the ciliary body require primary attention and aggressive treatment. In both cases, secondary destructive changes in the vessels can occur, causing reduced perfusion of the retina and chorioidea. Primary inflammatory vascular changes may lead to secondary morphologic chorioretinal changes which may then further impair function. The inflammatory process and/or the reduced chorioretinal perfusion are important. Therefore, an anti-inflammatory/ immunomodulatory therapy, a hemorheologic therapy, or a combination of both treatments, should bring about improvement of the condition, insofar as no other specific therapy is indicated. ${ }^{84}$

After excluding an infectious cause and general contraindications, Brunner and Borberg carried out a prospective randomized study with TPE in uveitis. ${ }^{85}$ The aim of this study was to examine improvement in blood flow properties and possible immunomodulation through the exchange solution in addition to elimination of a pathologic substrate. ${ }^{85,86}$
Detection of immune complexes or autoantibodies in uveitis is problematic. First, indications for the existence and possible pathomechanism of pathogenic substrates to retinal $\mathrm{S}$ antigen were found in patients with uveitis and in animal studies. Both improvement and deterioration in the condition can be regarded as an indication of elimination of a pathogenic substrate.

Jahn et al describe significant improvement in apparent full blood viscosity and plasma viscosity in patients with uveitis after TPE and attribute this mainly to elimination of fibrinogen through the exchange. ${ }^{86}$ Dumonde et al discuss the protective, immune-modulating role of inhibiting circulating immune complexes against antiretinal autoantibodies (retinal S antigen) in retinal vasculitis. ${ }^{87}$ On the other hand, immunoglobulins are therapeutically implemented both for antibody substitution and also for immune modulation in other nonocular diseases. ${ }^{88}$

The improvement in hemorheologic parameters could contribute considerably to the therapeutic success in autoimmune eye diseases accompanied by primary or secondary vascular changes. With improved microcirculation, the damaged tissue can recover. In addition, other mechanisms, such as elimination of a pathogenic substrate or immunomodulatory effects of the exchange medium, probably contribute to the success of this therapy.

A similar positive influence of TPE on therapy-resistant uveitis was observed by Bambauer et al. In eight of ten patients with uveitis who displayed no improvement despite immunosuppressive therapy, eye symptoms improved with TPE. After new attacks of uveitis, only a few TPE sessions were required to improve the condition and stabilize it for many months. ${ }^{33}$ Other investigators have reported similar results. ${ }^{89}$ TPE seems to be particularly indicated in noninfectious uveitis which does not respond to conventional therapy with cortisone and immunosuppressives. Basic therapy with cortisone and immunosuppressives along with TPE treatment seems to be advantageous.

In patients with disabling endocrine ophthalmopathy, plasma exchange may sometimes be of value to induce relief of ophthalmopathy. When it is used, it should be instituted before fibrotic changes occur. Berlin et al suggest that concomitant immunosuppressive drugs should be given to prevent the rebound phenomenon induced by TPE in the treatment of endocrine ophthalmopathy, and that controlled studies should be performed..$^{90}$

The immunomodulating mechanism of TPE, which favors a prompter elimination of inflammation, increases ocular function, and reduces recurrence, has been clarified. The 
mechanisms of action of TPE as a technique used alone and in combination with immunosuppression, laser, and ultraviolet blood irradiation are mentioned by Frolov et al. ${ }^{91}$

In recent years, the anti-TNF- $\alpha$ antibodies, infliximab and adalimumab, and others demonstrated significant efficacy in controlling uveitis associated with seronegative spondyloarthropathies and juvenile idiopathic arthritis. ${ }^{88}$ The majority of reports of biologic therapies in posterior uveitis have been uncontrolled or retrospective studies in patients with uveitis resistant to immunosuppression.

Biologic therapies have increased the treatment options for sight-threatening uveitis. Despite an experimental rationale, the lack of evidence from randomized controlled studies limits our understanding of when to commence therapy, which agent to choose, and how long to continue treatment. Additionally, the high cost and potential side effects of the biologic agents have limited their current use to uveitis refractory to immunosuppression. Further controlled randomized multicenter studies of TPE and/or immunosuppression versus biologics are necessary to clarify efficacy, side effects, and costs.

\section{Conclusion}

The prognosis of autoimmune diseases, such as SLE, antiphospholipid syndrome, rheumatoid arthritis, and inflammatory eye disease, with their varying organ manifestations has improved considerably in recent years due to very aggressive therapy schemes. These include therapeutic apheresis in combination with immunosuppressive therapies and/or biologic agents. In mild forms of autoimmune disease, immunosuppressive therapies and/or biologic agents seem to be sufficient. Therapeutic apheresis is only indicated in severe cases, such as rapid progression despite immunosuppressive therapy, and/ or biologic agents in renal involvement, acute generalized vasculitis, thrombocytopenia and leukopenia, pulmonary, cardial, or cerebral involvement. In these cases, therapeutic apheresis must be combined with an immunosuppressive therapy and/or biologic agent. Use of newer technologies, such as immunoadsorption, possibly in combination with recent biologics, might offer some new perspectives for extracorporeal treatment of systemic autoimmune diseases.

\section{Disclosure}

The authors report no conflicts of interest in this work.

\section{References}

1. Börsch G, Ricken D. Diagnostik bei Systemischem Lupus Erythematodes. Dtsch Med Wochenschr. 1983;108:789-794. German.

2. Davidson A, Diamond B. Autoimmune diseases. $N$ Engl J Med. 2001;345:340-350.
3. Nakamura RU, Binder WL. Diagnostik von Autoimmunerkrankungen. [Diagnosis of Autoimmune Diseases]. Diag Lab. 1987;37:107-111. German.

4. Hänsch MG, Peter HH. Physiologie und Pathophysiologie der Immunantwort. 1. Struktur und Funktion des Immunsystems. In: Peter HH, editor. Klinische Immunologie. Baltimore, MD: Urban and Schwarzenberg; 1991. German.

5. Berlit P. Lupus Erythematodes und Nervensystem. Dtsch Ärztebl. 1989;86:A3176-A3182. German.

6. Trautmann F, Eckhardt R. Diagnostik der systemischen Vaskulitiden. Dtsch Med Wochenschr. 1987;112:1253-1256. German.

7. Goronzy JJ, Weyand CM. B cells as a therapeutic target in autoimmune disease. Arthritis Res Ther. 2003;5:131-135.

8. Looney RJ. Treating human autoimmune disease by depleting B cells. Ann Rheum Dis. 2002;61:863-866.

9. Pantel DD. B cell-ablative therapy for the treatment of autoimmune diseases. Arthritis Rheum. 2002;46:1984-1985.

10. Bambauer R, Schiel R, Lehmann B, Bambauer C. Therapeutic apheresis, technical overview. ARPN J Sci Technol. 2012;2:399-421. Available from: http://www.ejournalofscience.org/archive/vol2no5/vol2no5_1. pdf. Accessed July 22, 2013.

11. Peter HH, editor. Klinische Immunologie. [Clinical Immunology]. Baltimore, MD: Urban and Schwarzenberg; 1991. German.

12. Ter Borg EJ, Horst G, Hummel EJ, et al. Measurement of increase in antidouble stranded DNA antibody levels as a predictor of disease exacerbation in systemic lupus erythematosus. Arthritis Rheum. 1990;33:634-643.

13. Peter HH. Systemischer lupus erythematodes. [Sytemic lupus erythemotosus]. In: Peter HH, editor. Klinische Immunologie. Baltimore, MD: Urban and Schwarzenberg; 1991. German.

14. Kuhn A, Beissert S, Krammer PH. CD4+CD25+ regulatory T cells human lupus erythematosus. Arch Dermatol Res. 2008;301:71-81.

15. Valencia X, Yarboro C, Illei G, Lipsky PE. Deficient CD4+CD25 high $T$ regulatory cell function in patients with active systemic lupus erythematosus. J Immunol. 2007;178:2579-2588.

16. Vogt A. Neue Konzepte zur Immunpathogenese der Lupusnephritis. [New concepts immune-pathogenesis of the lupus nephritis]. Mitt Klin Nephrol. 1992;21:19-26. German.

17. Volk HD, Soennichsen N, Jahn S, et al. The influence of interferongamma, interleukin-2, prostaglandin E2, and cyclosporine on the polyclonal and anti-DNA antibody secretion in lymphocyte cultures derived from patients with systemic lupus erythematosus. Arch Dermatol Res. 1987;279:S92-S96.

18. Szczepiorkowski ZM, Bandarenko N, Kim HC, et al; Apheresis Applications Committee of the American Society for Apheresis. Guidelines on the use of therapeutic apheresis in clinical practice-evidence-based approach from the Apheresis Applications Committee of the American Society for Apheresis. J Clin Apher. 2007;22:106-175.

19. Witte T, Schmidt RE. Pathophysiologie und Immunologie des SLE. Nieren-Hochdruckkrankh. 1995;24:660-667. German.

20. Kasinath BS, Neilson EG, Hebert L, Schwartz MM, Lewis EJ. Shortterm prognosis of severe proliferative lupus nephritis. Am J Kidney Dis. 1986;8:239-243

21. Arnett FC, Edworthy SM, Bloch DA, et al. The American Rheumatism Association 1987 revised criteria for the classification of rheumatoid arthritis. Arthritis Rheum. 1988;31:315-324.

22. Engel HJ. Früherkennung des systemischen Lupus erythematodes (SLE). Dtsch Med Wochenschr. 1988;113:485-491.

23. Euler HH, Schröder JO, Harten P, et al. Antibody depletion and cytotoxic drug therapy in severe systemic lupus erythematosus. Transfus Sci. 1992;13:167-184.

24. Sloan RP, Schwartz MM, Korbet SM, Borok RZ. Long-term outcome in systemic lupus erythematosus membranous glomerulonephritis. J Am Soc Nephrol. 1996;7:299-305.

25. Perez De Lema G, Maier H, Nieto E, et al. Chemokine expression precedes inflammatory cell infiltration and chemokine receptor and cytokine expression during the initiation of murine lupus nephritis. J Am Soc Nephrol. 2001;12:1369-1382. 
26. Kasgarin M. Lupus nephritis: Lessons from the path lab. Kidney Int. 1994;45:928-933.

27. Jones VJ, Cumming RH, Bucknall RC, et al. Plasmapheresis in the management of acute systemic lupus erythematosus? Lancet. 1976;1:709-711.

28. Aboue NJ, Lindsley HB, PollockA, et al. Plasmapheresis in active systemic lupus erythematosus: effects on clinical, serum and cellular abnormalities. Case report. Clin Immunol Immunopathol. 1981;19:44-54.

29. Bambauer R, Jutzler GA, Pees H, et al. Two years' experience with therapeutic plasma exchange and cyclosporine $\mathrm{A}$ in severe cases of systemic lupus erythematosus. In: Bambauer R, Malchesky PS, Falkenhagen D, editors. Therapeutic Plasma Exchange and Selective Plasma Separation. New York, NY: Schattauer; 1987.

30. Barr WG, Hubell EA, Robinson JA. Plasmapheresis and pulse cyclophosphamide in systemic lupus erythematosus. Ann Intern Med. 1988; 108:152-153.

31. Robinson AE. Current topics: potential for plasma exchange in children. Arch Dis Child. 1982;57:301-308.

32. Swaak AJ. The therapeutic potential of plasmapheresis in systemic lupus erythematosus (SLE). Neth J Med. 1988;33:155-159.

33. Bambauer R, Latza R, Lentz MR. Therapeutic Plasma Exchange and Selective Plasma Separation Methods, Fundamental Technologies, Pathology and Clinical Results. 3rd ed. Berlin, Germany: Pabst Sciences Publishers; 2009.

34. Zielinski CC, Mueller C, Smolen J. Der Einsatz der Plasmapherese in der Therapie des systemischen Lupus erythematodes: eine kontrollierte Studie. [Application of plasmapheresis in the treatment of the systemic lupus erythematosus: a controlled study]. Acta Med Austr. 1988;15:155-158. German.

35. Fosella PV, Ferri C, Moriconi L, et al. T-cell subject in systemic lupus erythematosus nephritis treated with plasma exchange. Plasma Ther Transfus Technol. 1986;7:127-134.

36. Leaker BR, Becker GJ, Dowling JP, Kincaid-Smith PS. Rapid improvement in severe lupus glomerular lesions following intensive plasma exchange associated with immunosuppression. Clin Nephrol. 1986;25:236-244.

37. Jones VJ. Immunological aspects of plasmapheresis. In: Bambauer R, Malchesky PS, Falkenhagen D, editors. Therapeutic Plasma Exchange and Selective Plasma Separation. New York, NY: Schattauer; 1987.

38. Schröder JO, Euler HH. Systemischer Lupus erythematodes. Internist (Berl). 1993;34:351-361. German.

39. Evans DT, Giles M, Horne DJ, d'Apice AJ, Riglar A, Toh BH. Cerebral lupus erythematosus responding to plasmapheresis. Postgrad Med J. 1981;57:247-251.

40. Parry HF, Moran CJ, Snath ML et al. Plasma exchange in systemic lupus erythematosus. Ann Rheum Dis. 1981;40:224-228.

41. Campion EW. Desperate disease and plasmapheresis. $N$ Engl J Med. 1992;326:1425-1427.

42. Lewis J. Plasmapheresis therapy is ineffective in SLE. J Clin Apher. 1992;7:153.

43. Dau PC, Callahan J, Parker R, Golbus J. Immunologic effects of plasmapheresis synchronized with pulse cyclophosphamide in systemic lupus erythematosus. Rheumatology. 1991;18:270-276.

44. Clark WF, Dau PC, Euler HH, et al. Plasmapheresis and subsequent pulse cyclophosphamide alone in severe lupus: design of the PSG trial. Lupus Plasmapheresis Study Group (LPSG). J Clin Apher. 1991;6: 40-47.

45. Euler HH, Krey U, Gutschmidt HJ, et al. A concept of synchronization of plasmapheresis with immunosuppression application in rapidly progressive glomerulonephritis. In: Bambauer R, Malchesky PS, Falkenhagen D, editors. Therapeutic Plasma Exchange and Selective Plasma Separation. New York, NY: Schattauer; 1987.

46. Braun J, Sieper J, Schwarz A, Keller F, Heitz J, von Ameln H. Severe lupus crisis with agranulocytosis and anuric renal failure due to a mesangial lesion (WHO IIB) - successful treatment with cyclophosphamide pulse followed by plasmapheresis. Br J Rheumatol. 1991;30: 312-313.
47. Euler HH, Schröder JO, Zeuner RA, et al. A randomized trial of plasmapheresis and subsequent pulse cyclophosphamide in severe lupus: design of the LPSG trial. Int J Artif Organs. 1991;14:639-646.

48. Aringer M, Smolen JS, Graninger WB. Severe infections in plasmapheresis-treated systemic lupus erythematosus. Arthritis Rheum. 1998:41:414-420.

49. Kovacs B, Lafferty TL, Brent LH, DeHoratius RJ. Transverse myelopathy in systemic lupus erythematosus: an analysis of 14 cases and review of the literature. Ann Rheum Dis. 2000;59:120-124.

50. Pagnoux C, Korach JM, Guillevin L. Indications for plasma exchange in systemic lupus erythematosus in 2005. Lupus. 2005;14:871-877.

51. Baráth S, Sotész P, Kiss E, et al. The severity of systemic lupus erythematosus negatively correlates with the increasing number of CD4+ $\mathrm{CD} 25$ high FoxP3+ regulatory $\mathrm{T}$ cells during repeated plasmapheresis treatments of patients. Autoimmunity. 2007;40:521-525.

52. Clark WF, Lindsay RM, Cattran DC, Chodirker WB, Barnes CC, Linton AL. Monthly plasmapheresis for systemic lupus erythematosus with diffuse proliferative glomerulonephritis. A pilot study. Can Med Assoc J. 1981;125:171-175.

53. Le Francois N, Deteix P, Laville M, et al. Treatment of systemic lupus erythematosus with cyclosporin A: a patient with a 1-year follow up. Kidney Int. 1984;26:225-231.

54. Bambauer R, Schwarze U, Schiel R. Cyclosporine A and therapeutic plasma exchange in the treatment of severe lupus erythematosus. Artif Organs. 2000;24:852-856.

55. Schiel R, Bambauer R, Latza R, Klinkmann J. Cyclosporine and therapeutic plasma exchange in treatment of progressive autoimmune diseases. Artif Organs. 1997;21:983-988.

56. Bambauer R, Weber U, Berberich R. Nephrotoxizität von Cyclosporin A in der Behandlung des Systemischen Lupus Erythematodes. [Nephrotoxicity of cyclosporin A in the treatment of the systemic lupus erythematosus]. Nieren-und Hochdruckkrankheiten. 1990;19:452-454. German.

57. Feutren G, Querin S, Noël LH, et al. Effects of cyclosporine in severe systemic lupus erythematosus. J Pediatr. 1987;111:1063-1068.

58. Noble S, Wagstaff AJ. Cyclosporin: a review of its pharmacology and clinical potential in the treatment of systemic lupus erythematosus. Bio Drugs. 1997;7:483-501.

59. Szczepiorkowski M, Winters J, Bandarenko N, et al. Guidelines on the use of therapeutic apheresis in clinical practice-evidence-based approach from the Apheresis Applications Committee of the American Society Apheresis. J Clin Apher. 2010;25:83-177.

60. Pons-Estel GJ, Salerni GE, Serrano RM, et al. Therapeutic plasma exchange for the management of refractory systemic autoimmune diseases: report of 31 cases and review of the literature. Autoimmun Rev. 2011;10:679-684.

61. Pagnoux C. Plasma exchange for systemic lupus erythematosus. Transfus Apher Sci. 2007;36:187-193.

62. Lockshin MD. Antiphospholipid antibody syndrome. Rheum Dis Clin North Am. 1994;20:45-49.

63. Ogawa H. A case of catastrophic antiphospholipid syndrome treated by immunoadsorption therapy. Jpn J Apher. 1995;14:75-79.

64. Espinosa G, Cervera R. Current management of catastrophic antiphospholipid syndrome. Int J Clin Rheumatol. 2011;6:297-303.

65. Scott DL, Coulton BL, Symmonds DPM, et al. Therapieergebnis bei chronischer Polyarthritis. [Therapy Results of the Chronic Polyarthritis]. Dtsch Med Wochenschr. 1987;112: 1723-1727. German.

66. Hidaka T, Suzuki K. Efficacy of filtration leukocytapheresis on rheumatoid arthritis with vasculitis. Ther Apher. 1997;1:212-214.

67. Lorenz HM, Geiler T, Kalden JR. Immunsuppressive Therapiemodalitäten bei chronischen Polyarthritiden [Immunesuppressive therapy modulation in chronic polyarthritis]. Internist (Berl). 1997;38: 352-540. German.

68. Kelly WN, Harris ED, Ruddy S, editors. Textbook of Rheumatology. Philadelphia, PA: Saunders; 1981. 
69. Tuscano JM, Sands S. B cell reductive therapy with rituximab in the treatment of rheumatoid arthritis. Biologics. 2009;3:225-232.

70. Guillevin L. Therapeutic plasma exchange: definite indications and rescue therapy in rheumatic diseases. Plasma Ther Transfus Technol. 1986;7:533-539.

71. Kondoh T, Hidaka Y, Katoh H, Inoue N, Saito S. Evaluation of a filtration lymphocytapheresis (LCP). Device for use in the treatment of patients with rheumatoid arthritis. Artif Organs. 1991;15:180-188.

72. Malchesky PS, Smith JW, Koo A, et al. Uncontrolled trial of cryofiltration in rheumatoid arthritis. J Clin Apher. 1988;4:156-165.

73. Rau R, Karger T. Klinische Erfahrungen und Differentialindikation der Therapie mit Metothrexat bei chronischer Polyarthritis. [Clinical experiences and differential diagnosis of the Therapy with metothrexat in the chronic polyarthritis]. Intern Welt. 1987;12:335-348. German.

74. Yu X, Ma J, Tian J, et al. A controlled study of double filtration plasmapheresis in the treatment of active rheumatoid arthritis. $J$ Clin Rheumatol. 2007;13:193-198.

75. Liu JD, Zhang C, Li WS, et al. Double filtration plasmapheresis for the treatment of rheumatoid arthritis: a study of 21 cases. ArtifOrgans. 1997;21:96-98.

76. Ogawa $\mathrm{H}$, Matsumoto $\mathrm{Y}$. The efficacy of plasmapheresis or leukocytoapheresis for articular and extraarticular manifestation of rheumatoid arthritis. Ther Apher. 1997;1:330-335.

77. Onuma S, Yamaji K, Kempe K, et al. Investigation of clinical effect of large volume leukocytapheresis on methotrexate-resistant rheumatoid arthritis. Ther Apher Dial. 2006;10:404-411.

78. Suzuki M, Wakasugi K, Fjuitsuka M, et al. Treatment of rheumatoid arthritis by cryofiltration: a controlled trial. In: Oda T, Shikowas Y, Inoue N, editors. Proceedings of the First International Congress of the World Apheresis Association: Therapeutic plasmapheresis. Cleveland, $\mathrm{OH}$ : ISAO Press; 1987.

79. Caldwell J, Gendreau RM, Furst D, et al. A pilot study using a staph Protein A column (Prosorba) to treat refractory rheumatoid arthritis. J Rheumatol. 1999;26:1657-1662.

80. Youssef P, Kennedy D. Arthritis in pregnancy: the role and safety of biological agents. Obstet Med. 2009;2:134-139.

81. Hashizume M, Uchiyama Y, Horai N, et al. Tocilizumab, a humanized anti-interleukin-6 receptor antibody, improved anemia in monkey arthritis by suppressing IL-6-induced hepcidin production. Rheumatol Int. 2010;30:917-923.
82. Wizemann AJS, Wizemann V. Plasmaaustauschbehandlung bei chronischer Uveitis. [Plasma exchange therapy in the chronic uveitis]. Fortschr Ophthalmol. 1984;81:449-454. German.

83. Bodaghi B, Gendron G, Wechsler B, et al. Efficacy of interferon alpha in the treatment of refractory and sight threatening uveitis: a retrospective monocentric study of 45 patients. Br J Ophthalmol. 2007;91: 335-339.

84. Spalton DJ. Progress in uveitis. Br J Ophthalmol. 1988;72:921-925.

85. Brunner R, Borberg H. Plasma exchange therapy in ophthalmology. Plasma Ther Transfus Technol. 1988;9:59-70.

86. Jahn $\mathrm{M}$, Brunner R, Borberg $\mathrm{H}$, et al. Beeinflussung hämorrheologischer und laborchemischer Parameter durch Infusionstherapie mit Serumkonserve und durch Plasmaaustausch mit Humanalbumin und Serumkonserve bei Patienten mit Uveitis posterior und intermedia. [Modification of hemorrheologic and laboratory chemical parameters by infusion therapy and preserved serum and by plasma exchange with human albumin and preserved serum in patients with posterior and intermediate uveitis]. Fortschr Ophthalmol. 1988;85:740-743. German

87. Dumonde DC, Kasp-Grochowska E, Graham E, et al. Anti-retinal autoimmunity and circulating immune complexes in patients with retinal vasculitis. Lancet. 1982;2:787-792.

88. Imrie FR, Dick D. Biologics in the treatment of uveitis. Curr Opin Ophthalmol. 2007;18:481-486.

89. Raizman MB, Forster CS. Plasma exchange in the therapy of Behcet's disease. Graefe's Arch Clin Exp Ophthalmol. 1989;227(4):360-363.

90. Berlin G, Hjelm H, Liedén G, Tegler L. Plasma exchange in endocrine ophthalmopathy. J Clin Apher. 1990;5:192-196.

91. Frolov AB, Grechanyǐ MP, Chentsova OB. [Use of plasmapheresis-based extracorporeal hemoprotection in the treatment of endogenic uveitis and autoimmune eye diseases.] Vestn Oftalmol. 2009;125:57-60. Russian.

92. Bosch T, Braun N, Fassbinder W et al. Apherese Standard der Deutschen Arbeitsgemeinschaft für Klinische Nephrologie. [Apheresis standard of the German working group for clincal nephrology]. Mitt Klin Nephrol. 2002;103-138.
Open Access Rheumatology Research and Reviews

\section{Publish your work in this journal}

Open Access Rheumatology Research and Reviews is an international, peer-reviewed, open access journal, publishing all aspects of clinical and experimental rheumatology in the clinic and laboratory including the following topics: Pathology, pathophysiology of rheumatological diseases; Investigation, treatment and management of rheumatological

\section{Dovepress}

diseases; Clinical trials and novel pharmacological approaches for the treatment of rheumatological disorders. The manuscript management system is completely online and includes a very quick and fair peerreview system, which is all easy to use. Visit http://www.dovepress.com/ testimonials.php to read real quotes from published authors. 